\title{
Investigating levels of food variety consumed across European countries in an adult population
}

\author{
N. F. C. Devlin ${ }^{1}$, B. A. McNulty ${ }^{1}$, A. Turrini ${ }^{2}$, C. Tlustos ${ }^{3}$, A. P. Hearty ${ }^{1}$, J. L. Volatier ${ }^{4}$, \\ C. C. Kelleher ${ }^{1}$ and A. P. Nugent ${ }^{1}$ \\ ${ }^{1}$ UCD Institute of Food and Health, University College Dublin, Dublin 4, Republic of Ireland, ${ }^{2}$ INRAN, National Research \\ Institute on Food and Nutrition, Rome, Italy, ${ }^{3}$ Food Safety Authority of Ireland, Dublin, Ireland and ${ }^{4}$ ANSES, France
}

The aim of this study was to characterise the variety of foods consumed across European countries based on foods selected in a total diet study (TDS) approach, where data was provided by the EFSA Comprehensive Database ${ }^{(1)}$. This database was developed from national food consumption surveys and represents data for seven population groups across 22 European countries. TDS foods were selected if they satisfied the criteria of $90 \%$ of the weight of the total diet and a consumer rate $\geqslant 5 \%$. Selected TDS foods were grouped into 1 of 20 food groups. Differences in the number of selected TDS foods per food group per country are presented, with the view of defining representative food lists.

\begin{tabular}{|c|c|c|c|c|c|c|}
\hline \multirow[b]{2}{*}{ Food groups } & \multicolumn{6}{|c|}{ Number of TDS foods } \\
\hline & France & Germany & Italy & Ireland & Sweden & Czech Republic \\
\hline Grains and grain products & 13 & 17 & 8 & 6 & 9 & 10 \\
\hline Vegetable \& vegetable products & 13 & 7 & 15 & 5 & 3 & 7 \\
\hline Starchy roots and tubers & 4 & 3 & 1 & 3 & 4 & 2 \\
\hline Legumes, nuts and oils eeds & 4 & 0 & 1 & 1 & 0 & 0 \\
\hline Fruits and fruit products & 12 & 8 & 8 & 3 & 3 & 3 \\
\hline Meat and meat products & 9 & 9 & 6 & 7 & 3 & 7 \\
\hline Fish and other seafood & 2 & 0 & 2 & 1 & 1 & 1 \\
\hline Milk and dairy products & 9 & 10 & 6 & 4 & 6 & 3 \\
\hline Eggs and egg products & 1 & 1 & 1 & 1 & 1 & 1 \\
\hline Sugar and confectionary & 2 & 0 & 1 & 2 & 0 & 1 \\
\hline Fats and oils & 2 & 1 & 1 & 2 & 2 & 2 \\
\hline Fruit and vegetable juices & 5 & 3 & 2 & 1 & 1 & 1 \\
\hline Non-alcoholic beverages & 11 & 9 & 4 & 9 & 5 & 2 \\
\hline Alcoholic beverages & 8 & 5 & 3 & 4 & 4 & 3 \\
\hline Drinking water & 3 & 2 & 2 & 1 & 2 & 2 \\
\hline Herbs, spices \& condiments & 1 & 3 & 1 & 1 & 1 & 1 \\
\hline Food for infants \& children & 0 & 0 & 0 & 0 & 0 & 0 \\
\hline Nutritional products & 0 & 0 & 0 & 0 & 0 & 0 \\
\hline Composite food & 0 & 5 & 1 & 2 & 7 & 0 \\
\hline Desserts \& other foods & 2 & 2 & 1 & 1 & 1 & 0 \\
\hline Total TDS foods & 101 & 85 & 64 & 54 & 53 & 46 \\
\hline
\end{tabular}

Total number of foods consumed in each country were: 1233, 19334, 975, 1681, 1055, 443 respectively.

The results indicate that the French appear to have the greatest variety in their diet with 101 TDS foods selected, while the Czech Republic shows a lesser variation with just 46 foods selected. Although differences in survey methodology may have contributed to these figures, the results may suggest that France consume a more varied diet in comparison to the other countries studied here. This may support earlier research on the French paradox ${ }^{(2)}$ but also suggests that any TDS list for France will be longer than that for any other European country.

The research leading to these results received funding from the European Union Seventh Framework Programme (FP7/2007-2013) under Grant Agreement 289108 (Total Diet Study Exposure). This publication reflects only the authors' views, and the Community is not liable for any use made of the information contained therein.

1. EFSA Comprehensive European Food Consumption Database (2011) European Food Safety Authority.

2. Ferrieres J, (2004) Heart 90, 107-111. 